\title{
INTRODUCTION TO THE ROUTLEDGE HANDBOOK OF PHILOSOPHY OF SKILL AND EXPERTISE
}

\author{
Ellen Fridland and Carlotta Pavese ${ }^{1}$
}

The diverse and breathtaking intelligence of the human animal is often embodied in skills. People, throughout their lifetimes, acquire and refine a vast number of skills. And there seems to be no upper limit to the creativity and beauty expressed by them. Think, for instance, of Olympic gymnastics: the amount of strength, flexibility, and control required to perform even a simple beam routine amazes, startles, and delights. In addition to the sheer beauty of skill, performances at the pinnacle of expertise often display a kind of brilliance or genius. We observe an intelligence that saturates the body. The unity of physicality and intellect, mind and body, meshed and melded.

Apart from sports, people develop a host of other skills, including musical and artistic skills, linguistic and social skills, scientific and medical skills, military and political skills, engineering skills, computer skills, business skills, etc. What's more, skill acquisition and refinement occur throughout the human lifespan. Children work on skills from infancy and throughout development and adults will often continue to refine skills through old age. The variety, ubiquity, and centrality of skills in the lives of humans is quite simply remarkable.

Although notions of skill and expertise have always figured prominently in a variety of philosophical discussions, the last couple of decades have seen an explosion of direct interest in skill and practical expertise. Crucially, debates about know-how and virtue epistemology have fueled interest in the notion of skill and practical knowledge in areas such as epistemology, ethics, and action theory. Also, philosophers of cognitive science, as well as neuroscientists and psychologists, have become increasingly interested in issues concerning the nature of embodied expertise, motor skill, motor representation, and bodily control. As a result, across a variety of subfields from ancient and eastern philosophy, philosophy of mind, cognitive science, philosophy of perception, epistemology, action theory, ethics, political and social philosophy, and aesthetics, the debate concerning skill and practical intelligence is growing and thriving.

It is the aim of this Handbook to collect and systematize the most relevant positions in these burgeoning areas of philosophy and cognitive science. Contained within are 39 chapters written by leaders in their fields, addressing the role of skill in the history of philosophy both East and West, epistemology, political philosophy, ethics, and various areas of the cognitive sciences, 
including perception, imagination, emotion, motor control, language, and social cognition. The chapters offer both accessible overviews of the most relevant, current debates in their respective areas and, in many cases, also develop novel, substantive positions.

It should be noted that questions of skill and expertise are important not only for our particular, theoretical understanding of these specific notions but, more broadly, for our understanding of intelligence, cognition, and practical knowledge, full stop. That is, in thinking seriously about skill and expertise, we develop a fuller, richer picture of the nature of human cognition: moral, social, political, and embodied. This understanding, rooted in both theoretical and empirical views, provides us with the opportunity to properly and substantively conceptualize the nature of practical intelligence. This, in turn, allows and sometimes forces us to reformulate our current understanding of more familiar notions, such as knowledge, action, intention, virtue, perception, imagination, emotion, and even mental representation and intelligence. In all, then, questions concerning skill are significant in and of themselves, but also highly relevant for our overall understanding of the human mind.

Below, we introduce and contextualize the parts and chapters covered by this Handbook.

\section{I.1 Skill in the history of philosophy (East \& West)}

\section{I.1.1 Skill in the history of Eastern philosophy}

Skill and expertise have played a prominent role in several traditions of Eastern thought, especially as those notions are connected to living the good, virtuous, or ethical life. For instance, skillful means or upaya in Indian Buddhism, examples of expert swimmers or butchers in Daoism, and karate and calligraphy in the Chan/Zen tradition are all taken either directly or indirectly to concern the cultivation of appropriate awareness, attention, and perception, which is thought essential for living the good life. Across traditions, spontaneity, naturalness, effortlessness, and absorption are central to the notion of skill, though exactly how these features ought to be understood is still a matter of some debate. The authors who have written about skill in the history of Eastern philosophy in this Handbook have provided us both with badly needed context and accessible but substantive overviews of the particular ways in which skill is relevant to various discussions in Indian, Chinese, and Japanese philosophy. Moreover, each chapter offers its own way of making sense of the balance and/or tension between spontaneity and wisdom.

In their chapter, "Skill and Virtuosity in Buddhist and Daoist Philosophy," Jay L. Garfield and Graham Priest examine the various roles that skill plays in the Indian school of Mahayana Buddhism, in Daoism, and in Chan/Zen thought. In Indian Buddhism, the notion of upaya or skillful means is important for understanding not only skilled pedagogy, that is, teaching in a way that is appropriate to the understanding of the student, but also for grasping fundamental truths concerning the nonduality of practice and awakened consciousness. In this way, the ultimate state of personal wisdom is a state of skillful engagement with the world. This skillful engagement is necessarily a moral engagement, though it is not simply the possession of virtue but, rather, the embodied moral skill of the virtuoso-effortless, natural, spontaneous, and responsive to context.

In Daoism as well as in Chan/Zen Buddhism, the emphasis on skill is also connected, fundamentally, to concerns about living a good and ethical life. The characteristics of spontaneous, natural, absorbed, attentive, engaged, and mindful action that are found in skill are exactly those features that are required for living in an ethical and natural way. Garfield and Priest go on to present a substantive proposal for how to understand the spontaneity of skill—they claim that 
acting without reflective thinking does not imply that skilled action is thoughtless. Moreover, the skilled person knows both when and how to deliberate. Thus, thought and skill are not necessarily at odds, though skill is necessarily immediate and spontaneous. In fact, they claim that in eastern traditions, "practical knowledge embodied in skill is our principal cognitive achievement."

Further examining the role of skill in Daoism but also in other schools within the Chinese tradition, Hagop Sarkissian provides an overview of skill and expertise in Chinese philosophy from the 6th-3rd centuries BCE. His chapter, "Skill and Expertise in Three Schools of Classical Chinese Thought," focuses on two prominent types of expertise that are often encountered in ancient Chinese thought: The first is expertise at a particular craft, occupation, or dao, as is most famously presented in the Daoist anthology Zhuangzi. The second is ethical expertise in the Ruist (Confucian) and Mohist schools.

Sarkissian provides several accessible examples of skilled agents as they are described in key Chinese texts. This gives the nonspecialist reader an opportunity to grasp the range of cases where an appeal to the spontaneity, absorption, and effortlessness of skill becomes relevant to understanding the truly good and ethical life. Interestingly, Sarkissian also connects the intuitiveness and spontaneity of skilled action to Antonio Damasio's (1999) somatic marker hypothesis, offering a way for us to understand how decision-making can become fine-tuned through practice and arise immediately with the appropriate emotional valence.

Next, Matthew MacKenzie's chapter, "Volition, Action, and Skill in Indian Buddhist Philosophy," examines the specific tensions in Buddhist philosophy between acting skillfully, with intention, volition, causal efficacy, and the production of karma and also without a self (anatman). In the course of deflating this tension, MacKenzie provides a primer in Buddhist psychology, ethics, and soteriology. First, MacKenzie argues that intentional action is central to the Buddhist conception of the human condition and the attendant prescriptions for how to liberate oneself from those conditions. However, the doctrine of no-self, which reduces the self to a collection of physical and psychological events is also incompatible with a fullblooded notion of agent-causation. In this way, the Buddhist is both robustly committed to intentional and skillful actions while also holding that the only causes of action are a complex of psycho-physical events (i.e., not a self). As such, agents should not be identified with selves but, rather, with the complex psycho-physical system in which phenomena arise and lead to other phenomena.

MacKenzie goes on to explain that this complex system or continuum of psycho-physical events (the practical agent) is required to develop both wisdom and skillful means (upaya) in order to produce liberated action. However, there is a further paradox in that such action, in its maximal skillfulness, should be without intention, volition, and effort. Rather, such action is spontaneous, wise, compassionate but without even the practical illusion of a self. MacKenzie ends by providing two ways of understanding the transition from unawakened to awakened agency: one constructivist, which he connects to Hubert Dreyfus' conception of expertise and the other innateist.

\section{I.1.2 Skill in history of Western philosophy}

The topic of skill and expertise (techne) in Plato and Aristotle has received attention both in relation to the notion of virtue and in the interpretation of Plato's and Aristotle's theories of knowledge. Although both Plato and Aristotle took techne to be a kind of knowledge, there is significant controversy about their conceptions regarding the nature of this kind of knowledge and its relation to experience (empeiria) on one hand, and scientific knowledge (epistēmēe) 
on the other (Johansen 2017; Lorenz and Morison 2019; Coope forthcoming). The work of Julias Annas $(1995,2001,2011)$ has renewed interest on the relation between skill and virtue (or phronessis) in the Nicomachean Ethics and also to Aristotle's action theory. Two chapters in our Handbook discuss Plato and Aristotle's views precisely on the relation between techne and phronesis.

In "Techne in the Platonic Dialogues," Tom Angier introduces us to the complexities of Plato's views on techne. Angier argues that Plato's conception of skill and expertise goes against modern expectations in at least two ways. First, the Greek concept of techne has a wider extension than the English "skill" or "expertise." In the dialogues, Socrates uses it not only to refer to crafts that yield a physical product but it is also used for activities whose outcome is either internal to the activity such as lyre-playing, or even purely theoretical, such as mathematics. The second respect under which Plato's conception of skill goes against modern expectations, according to Angier, is that while ethics and skill or expertise are not always conjoined in modern philosophy, Plato's interest in techne is primarily ethical. In a striking analogy with what we have seen above as a unifying theme in the Buddhist, Daoist, Chan/Zen, Ruist, and Mohist traditions, a central question throughout the Platonic corpus is: can virtue be construed as a kind of skill or expertise?

Angier makes a systematic case that Plato saw in techne a model of precision that approximates a science (epistēme $\bar{e}$ ). As Angier points out, there are several benefits of thinking of virtue in this fashion. First, a science of virtue would professionalize the ethical life and so secure it firmer grounds. To be technikos is contrasted with having a mere empeiria or "knack" and so if virtue were a matter of having a techne, it would be taken out of the hands of those with a mere knack (or empeiros). For Plato, like later for Aristotle, technē involves a logos, or a rational account of one's expertise. Possessing a rational grasp of what one is doing would be highly beneficial to the virtuous person, for it would give them mastery and control of their practice. Moreover, techne embodies knowledge and, because of this, it is transmissible through teaching. Angier points out that for Plato the transmissibility of techne, primarily illustrated by theoretical technai such as mathematics, is the paradigm source and locus of agreement. The upshot is, perhaps surprisingly, both political and social: if virtue were subject to the rigors of a techne, we would be spared much social disagreement and conflict.

In Chapter 5, "Technê in Aristotle's Taxonomy of Knowledge," Thomas Johansen moves from Plato to Aristotle and highlights the differences in their conceptions of the relation between technē and phronessis. The chapter starts by revisiting Aristotle's notion that rational capacities are to do with truths and are accompanied by a true account (logos). Among rational capacities, Aristotle distinguished between theoretical knowledge, productive knowledge, and practical knowledge. While theoretical knowledge is concerned with necessary and eternal truths, productive and practical knowledge are concerned with contingent truths that can be under our influence and that can be changed. So while theoretical knowledge is a demonstrative state of reason concerned with eternal truths accompanied by a true account, and practical knowledge is a practical state of reason accompanied by a true account, productive knowledge is a productive state of reason accompanied by a true account.

So, while for Aristotle both technē and phronessis are rational capacities involving an account, technē involves a distinctive sort of intelligence. Technē and phronēsis differ in at least two respects. While phronessis is of an end without qualification (telos haploss), technē is of "an end in relation to something and of something" (telos pros ti and tinos); second, techne is of production and phronesis is of action. Johansen guides us through several possible interpretations of these putative differences between technē and phronessis and highlights several difficulties. As Johansen 
points out, the crucial point of contention of Aristotle's response to Plato might also have been the most philosophically problematic for Aristotle.

Despite Aristotle's attack, the Platonic idea that virtue can be conceived of as a certain sort of skill reemerges in modern thought in an exchange deftly reconstructed by Melissa Meritt in "Mendelssohn and Kant on Virtue as a Skill." As Meritt teaches us, Moses Mendelssohn played a pivotal role in rehabilitating the "skill model" of virtue for the German rationalist tradition. According to Mendelssohn, the execution of skill characteristically displays a certain automatism and unreflectiveness. Mendelssohn took this feature of skill, together with the skill model of virtue, to provide the resources for overcoming an objection against agent-based ethics, namely, that a virtuous person would seem to act for the sake of realizing his own perfection in everything that he does, thereby taking a morally inappropriate interest in his own character. By contrast, Kant rejects the automatism featured in Mendelssohn's account, on grounds that it would make virtue mindless and unreflective. As Merritt points out, that does not mean that Kant was thereby led to reject the skill model of virtue. Rather, Kant argued that reflection is central to the manifestation of certain kinds of skills too and, because of that, he was able to cling to a version of the virtue as skill model.

The next chapter of this historical section moves to the contemporary philosophy of skill. In "Gilbert Ryle on Skill as Knowledge-how," Michael Kremer deepens our understanding of Ryle's theory of skill. For Ryle, skill is a form of knowledge, or knowledge-how, that is constitutively acquired through practical and experimental learning and that depends on a critical capacity for self-regulation and continued improvement. Kremer makes the case that, while Ryle's notion of knowledge-how is sharply distinguished from knowledge-that, for him, knowledge-how is also substantively related to knowledge-that. Kremer reconstructs two of the classic Rylean arguments against the intellectualist legend-the regress argument and the argument from learning and gradability — and puts Ryle in a dialogue with recent debates concerning intellectualism and anti-intellectualism about know-how. Kremer argues that Ryle considered the intellectual and perceptual skills needed to produce knowledge-that to be kinds of know-how and that those intellectual skills, on his account, were the barriers to the regress which he thought afflicted intellectualism. Although knowledge-that depends on skills, Ryle also thought that skilled behavior depends in some ways on knowledge-that, especially since critical reflection on one's successes and failures requires an awareness of what one is doing and what its results are. Kremer's discussion of Ryle's conception of skill ends by looking at some of Ryle's less well-known writings (e.g., Ryle 1967, 1970, 1972) in order to reconstruct how Ryle's reflection on philosophical skill relates to his experience as a teacher and to his theoretical approach to the teaching of philosophy.

In the next chapter, Will Small discusses "Anscombe on Action and Practical Knowledge." While for Ryle know-how is a standing general knowledge that is put into practice on different occasions of action, Anscombe's notion of practical knowledge is that of a distinctive kind of agential knowledge that an agent has of her particular intentional actions while she performs them. Anscombe held that if someone is X-ing intentionally, she knows without observation not only that she is $\mathrm{X}$-ing; she knows without observation why she is $\mathrm{X}$-ing. Small explains that Anscombe arrives at this well-known "non-observational claim" through a negative specification of the "rough outline" of the "area of intentional actions." For Anscombe, the class of things that can be known without observation is a very heterogeneous class; hence, to know that intentional actions fall in that class is not to know much at all about what it is to be an intentional action, for it is not to know anything about why intentional actions fall in that class. The remainder of Intention (Anscombe 1957) develops a positive account of intentional action and 
agential knowledge. On this account, agential knowledge is knowledge "in intention"-hence not just knowledge of intention but knowledge in intention of what is going to happen. This knowledge is practical not just because its object is practical. It is practical in form, for it relates to its object in a different way from that in which theoretical knowledge relates to its-in the case of practical knowledge, the knowledge itself is the cause of what it understands. In this sense, agential knowledge is non-observational because it is practical: what is going on is a case of intentional action, there to be observed, only because it is already known agentially.

Does agential knowledge, as Anscombe understands it, depend on skill/know-how? Small provides evidence that, for Anscombe, one can intentionally do $A$ only provided that one knows how to $A$, otherwise it would surely be some accident if her activity culminated in her having successfully done $A$. So Anscombe did endorse an entailment-that from intentionally $A$ to knowing how to $A$-that is widely endorsed in the current debate on knowing-how by both intellectualists and anti-intellectualists (Ryle 1949; Stanley and Williamson 2001; Setiya 2012; Pavese 2018). According to Small, however, Anscombe's conception of know-how, though fully compatible with certain versions of intellectualism, fits most naturally with a "bifurcationist" conception of know-how, according to which there is propositional know-how but also nonpropositional "basic know-how."

While Anscombe insists that exercises of know-how are intentional, this is denied by Dreyfus (2001); and while Anscombe argued that an agent exercising know-how knows that she is doing what she is doing and why, Dreyfus (2007) explicitly rejected this model of intentional action. These and other complexities of Dreyfus' view on agency are discussed by Kristina Gehrman and John Schwenkler in their chapter, "Hubert Dreyfus on Practical and Embodied Intelligence." Gehrman and Schwenkler locate Dreyfus' account of "skilled coping" as part of a bigger picture that aimed to demonstrate the primacy of practical intelligence over all other forms of intelligence. It is in response to a standard picture of intentional action defended by his U.C. Berkeley colleague John Searle that Dreyfus came to elaborate his alternative to what he considered a standard and prevailing Platonic picture of human beings as essentially rational, individual agents. Like many contemporary action theories, Searle thought that an action is intentional only if the agent is in a mental state that represents the goal of her action; he also thought that this mental state is the cause of the bodily movement whereby the agent acts as she intends to and, in acting intentionally, an agent enjoys an experience that represents her action as the cause of her bodily movement. Dreyfus attacked all of these claims, arguing that they are not supported by the phenomenology of purposive activity. If we returned to the phenomenon with open minds, Dreyfus thought that what we would find would be that human beings can relate to the world in an organized purposive manner without their actions being accompanied by a representational state representing the goal of the action. Paradigmatic examples of these representation-less and yet purposive activities were, for Dreyfus, skillful activities like playing tennis or habitual activity like rolling over in bed or making gestures while speaking. In this sort of skillful coping, Dreyfus thought we find humans fundamentally embedded, absorbed, and embodied. Gehrman and Schwenkler document how these commitments to a non-mentalistic form of intentionality are present throughout Dreyfus' philosophical writings, from his critique of Artificial Intelligence research in the 1970s and 1980s to his rejection of John McDowell's conceptualism in his 2005 APA Presidential Address. Because Dreyfus was, in the end, most interested in presenting an at least equally plausible phenomenological account of skillful coping that could represent a viable alternative to the standard Platonic picture, Gehrman and Schwenkler guide us through Dreyfus' radical proposal for a contentless and non-mentalistic form of intentionality and practical intelligence, through to its deepest motivations. 


\section{I.2 Skill in epistemology}

Knowledge and skill are intimately connected. Scientists cannot collect new knowledge without developing their skills for devising experiments. And skilled artists, scientists, and mathematicians must know a lot about their area of expertise in order to perform skillfully and to routinely manifest that knowledge through their skillful performances.

Despite this obvious interrelationship, knowledge and skill have received different treatment in analytic epistemology. Although philosophers in this tradition have long been in the business of understanding and defining knowledge, the topic of skill has been marginalized. It is only quite recently that skills have made a powerful entrance in two epistemological debates: the debate on virtue epistemology and the debate on the nature of know-how. Part II encompasses four different chapters that take positions on these two central epistemological debates.

According to virtue epistemology, skill and know-how come before knowledge: knowledge is to be understood as a kind of skillful performance (Zagzebski 1996; Sosa 2007, 2015; Pritchard 2012; Turri 2018). This approach to epistemology is represented by two chapters of this handbook. In "Knowledge, Skill, and Virtue Epistemology," Duncan Pritchard provides an overview of different ways of understanding the virtue epistemological thesis that knowledge is to be conceived of in terms of the relationship between cognitive success and cognitive agency. Virtue epistemology is motivated by one key platitude: the ability intuition-according to which guesswork, for example, cannot amount to knowledge, for in it the subject displays no cognitive agency. According to robust virtue epistemology, there is nothing more to knowledge than virtuously formed true belief. Robust virtue epistemology is motivated by the idea that knowledge is a distinctive kind of cognitive achievement. Although theoretically attractive, Pritchard points out that it faces several objections, in that it cannot always account for another prominent intuition, the anti-luck intuition - the intuition that lucky belief cannot amount to knowledge. In this chapter, Pritchard argues that a form of modest virtue epistemology-anti-luck virtue epistemology - that combines the ability intuition with the anti-luck intuition, fares better. On these sorts of virtue epistemologies, knowledge is to be understood as safe (non-lucky) cognitive success which is attributable to one's manifestation of the relevant cognitive skills. According to Pritchard, anti-luck virtue epistemology thus has the resources to account for how knowledge demands both the avoidance of high levels of epistemic luck (and thus epistemic risk) and the manifestation of significant levels of relevant cognitive skill.

The second chapter on virtue epistemology is "Skill and Knowledge" by Ernest Sosa and Laura Frances Callahan. Following Sosa's $(2007,2015)$ prominent work in virtue epistemology, Sosa and Callahan take knowledge to be a form of action, which one might attempt and fail. Attempts can be either accurate, as when the aim of the attempt is attained, adroit, as when the attempt manifests a competence, or apt, where accuracy of the attempt manifests the competence. A competence is defined as a disposition to succeed and is understood as having a tripartite structure, for whether one is competent to perform on a certain occasion depends not only on one's pertinent skills (Skill) but also on the shape one is in (Shape) and on the favorability of one's relevant situation (Situation). Here, the authors present a detailed, and in some respects novel, robust virtue epistemological account. On this view, skills are not the same as competences. While competences have a triple structure, only the innermost competence counts as a skill: for one might have a skill without being in good shape or while being in a bad situation. Because of this, Sosa and Callahan observe that only full competence, rather than mere skill, is the most important kind of power for epistemology, for the highest epistemic success (knowledge) manifests full competence: one knows if and only if one has a true belief in virtue of one's having exercised skill in an appropriate shape and situation. This account differs from 
Pritchard's anti-luck virtue epistemology where both a virtue condition and an anti-luck condition play a role in defining knowledge. It also differs from modal virtue epistemologies (e.g., Beddor and Pavese 2018) that understand skillfulness in modal terms as counterfactual success. In fact, on Sosa and Callahan's proposal, the modal profile of a performance is irrelevant to its counting as apt.

A novel aspect of the virtue epistemological account defended by Sosa and Callahan in this chapter is that they appeal to knowledge in an understanding of justification: epistemic performances that manifest skill without aptness are mere justified beliefs, which fall short of knowledge. The resulting virtue epistemology gives knowledge a central explanatory role to play vis-à-vis other concepts central to epistemology, such as that of justification. In this sense, Sosa and Callahan's counts as a "knowledge-friendly" virtue epistemology.

In addition to their role in virtue epistemology, skills and know-how have been central to epistemological discussions concerning the nature of know-how and skill. As we have seen, Ryle (1949) defended a form of anti-intellectualism about skill: skill is a kind of know-how and know-how is irreducible to propositional knowledge. Despite Ryle's attack on the intellectualist legend, the last twenty years have seen a resurgence of intellectualism (Stanley and Williamson 2001; Stanley 2011a; Pavese 2013), in a variety of forms. Stanley and Williamson (2001) responded to Ryle by arguing that know-how and skill come apart and that knowledgehow consists in a distinctive kind of propositional knowledge about how to perform actions a state of knowing an answer to the question how one could perform the action under a distinctively practical mode of presentation. Moreover, they argued that one of Ryle's main motivations - he regress argument-fails.

This form of intellectualism was primarily motivated by linguistic considerations about how to ascribe know-how in English and kin languages. It focused on know-how and it conceded to Ryle that skills are a different matter from know-how. It even denied that know-how entails practical ability. A rich literature ensued, featuring responses and attacks to this version of intellectualism, some questioning the original linguistic argument (e.g., Schiffer 2002; Rumfitt 2003; Brogaard 2009; Bengson and Moffett 2011; Wiggins 2012; Hornsby 2016); others reformulating the Rylean regress argument (Fridland 2013; Weatherson 2017); others still questioning the epistemic parallel between know-how and knowledge-that (Poston 2009; Cath 2011, 2015; Setiya 2012; Carter and Pritchard 2015; Carter and Navarro 2018), the intelligibility of practical modes of presentation (Schiffer 2002; Noë 2005; Glick 2015), the compatibility of intellectualism with fundamental posits in cognitive science (e.g., Devitt 2011) and Stanley's (2011b) and Stanley and Krakauer's (2013) characterization of automatic processes (Fridland 2014, 2017a, 2017b). These attacks have, in turn, generated more intellectualist responses, aiming at defending the linguistic argument for intellectualism (Stanley 2011a, 2011b), the intelligibility of practical modes of presentation (Pavese 2015, 2019), at providing extra-linguistic motivations for the view (Pavese 2013), at defending the epistemic parallel between know-how and knowledge-that (MarleyPayne 2016; Pavese 2018), at debunking the cognitive science argument (Stanley and Krakauer 2013; Pavese 2019), the gradability argument (Pavese 2017), or the most recent versions of the regress argument (Cath 2013; Beddor and Pavese 2020).

The debate on know-how is ongoing. But the recent years have seen an important shift in attention. While earlier intellectualists agreed with Ryle that skill and know-how come apart, now intellectualists have extended their focus from know-how to skill. There is, however, wide disagreement on how intellectualism about skills ought to be understood. Stanley and Krakauer (2013) argue that skill consists in part in knowledge about how to perform an action but is not exhausted by it. In addition to knowledge, "motor acuity" is needed, as a sort of motor ability that can be tuned through practice and exercise. In contrast with this "hybrid view" of skill, 
Stanley and Williamson (2017) argue that skills are not themselves knowledge states but rather dispositions to know. Starting from considerations stemming from the role of knowledge in action theory, Pavese (2013) and Beddor and Pavese (2020) argue instead for a radical form of intellectualism, according to which both skill and know-how are knowledge states, for only knowledge states appropriately characterized can explain the distinctive intentionality and control of skillful performance.

Though different in several respects, these forms of intellectualism all agree in taking skill and know-how to be understood in terms of a fundamental epistemic state of knowledge. By contrast, in the chapter "Know-how and Skill: The Puzzles of Priority and Equivalence,"Yuri Cath defends a still different form of intellectualism - a "practical attitude intellectualism" as he calls it. Cath agrees with radical forms of intellectualism that skill and know-how are one and the same. However, Cath's intellectualism differs from radical intellectualism on two scores. First, Cath's intellectualism is revisionary, for according to Cath know-how and skill are not knowledge states but rather belief states of a kind. In particular, Cath appeals to his earlier work (Cath 2011, 2015) to argue that know-how can be Gettiered, while knowledge-that cannot. Because he thinks that know-how and knowledge-that differ in their epistemic and modal profile, Cath argues that know-how and skill cannot be knowledge states but must, rather, be belief states. Second, while intellectualists typically appeal to distinctively practical modes of presentation when characterizing the sort of knowledge states know-how and skill consist in, Cath develops a form of intellectualism that does not appeal to practical modes of presentation. For one to know how to perform a certain task one need not entertain a proposition under a practical mode of presentation; rather, it is enough that one entertains the propositional attitude practically.

While radical intellectualism understands skills in terms of knowledge, in the last chapter of Part II, "Knowledge as Skill," Stephen Hetherington reverses the order of explanation by defending practicalism - the view that knowledge is a kind of skill or know-how and defends it from several objections. While knowledge of a fact or truth has long been conceived of as a belief with epistemically propitious features, Hetherington argues that this picture fails to explain the distinctive role of knowledge vis-à-vis action. According to Hetherington, a paramount question for a theory of knowledge that is often neglected by epistemologists is: how can knowledge so conceived ever motivate and guide action? This chapter introduces a novel answer to this question - practicalism - whereby any instance of knowledge is a skillful power to act, or a form of knowledge-how. Hetherington argues that this pragmatist conception of knowledge can tell a powerful story about what links knowledge and action: many actions are expressions or manifestations of knowledge, which is itself the power to act in such ways.

While skills figure prominently in virtue epistemology, in the debate between intellectualists and anti-intellectualists, and in discussions about the relation between knowledge and action, the interest in skill in epistemology goes beyond these debates and expands to social epistemology. The notions of skill and expertise are central to today's discussions about what counts as a political expert (e.g., Goldman 2001; Buchanan 2004, 2009; Guerrero 2016) as well as in the debate about virtue ethics and moral expertise (Driver 2013, 2015). The importance of skill and knowhow for moral and social/political epistemology will reappear in the final part of this Handbook.

\section{I.3 Skill, intelligence, and agency}

The notions of skill and know-how figure prominently in the philosophy of action. As we have seen, for Anscombe (1957), intentional action is understood in terms of agential knowledge and, 
moreover, it requires know-how. By contrast, Dreyfus $(2000,2001,2005,2007)$ thought that skillful action is the locus of embodied, embedded agency and used such action as an example motivating a non-representational theory of intentional action. Because of the centrality of skills in an account of intentional and intelligent action, Part III of this Handbook is devoted to chapters that discuss skills in relation to theories of agency.

In the first chapter of this section, "Consciousness and Skill," Barbara Gail Montero launches a sustained attack on the broadly Dreyfusian account of skillful coping as mindless. Developing several lines of arguments from Montero (2016), the author targets the "the just-do-it principle," that permeates much of the Dreyfusian discussion of skillful and mindless coping. According to the just-do-it principle, experts perform best when their conscious minds are disengaged from their actions, when they are performing "automatically." Montero critically assesses several arguments for the just-do-it principle. One particular argument starts from the phenomenon of choking under pressure, where an individual performs significantly worse than would be expected in a high-pressure situation. This phenomenon has been taken to be evidence that skillful action proceeds without conscious attention, because choking episodes are thought to arise from the fact that anxiety leads one to focus and direct one's mind on the performance, which would otherwise proceed smoothly if mindless. The "explicit monitoring hypothesis" has it that in normal circumstances conscious monitoring interferes with high level of performance. Montero reviews the extant empirical literature and shows not only that the methodology underlying the experiments for the explicit monitoring hypothesis is controversial, relying on artificial experimental settings, but also that there are other possible explanations for the choking effects, which emphasize that changing the locus of the focus, more than the focus itself might be detrimental to the performance in choking under pressure. By carefully highlighting the shortcomings of this and other arguments for the just-do-it principle, Montero argues that online conscious thought about what one is doing is compatible with expertise and surveys some empirical evidence that in fact skillful performance might require the full consciousness of the expert.

Montero's critique of the just-do-it principle confronts Dreyfus and its other proponent in their own terms-i.e., by taking seriously phenomenological evidence and first personal reports and by looking at skillful performance from the perspective of the embodied experiences of the real experts. This "ecological" approach to the study of skillful performance is theorized and defended in the following chapter, "Embodied Experience in the Cognitive Ecologies of Skilled Performance," by John Sutton and Kath Bicknell. They argue that a properly ecological methodology requires looking at the real performances of experts in the environment where they are intelligently attuned, rather than in artificial and regimented experimental settings. It requires expanding standard sources for skill theory, to look not only at specialist work in sport psychology, music cognition or other rich bodies of applied research but also at practitioners' own fallible but unique self-understandings. In order to anticipate concerns about the reliability of self-reports, Sutton and Bicknell survey related methods from cognitive psychology, sport science, and cognitive ethnography, and home in on apprenticeship methods and work by researcher-practitioners. They illustrate the methodology by looking at an extended case study of cyclist Chloe Hosking's account of the closing stages of her winning ride in the 2016 La Course by Le Tour de France. Sutton and Bicknell argue that by triangulating Hosking's narrative against other evidence, one can learn about the multiplicity of diverse cues to which this athlete was responding in on-the-fly decision-making.

The link between skill and agency, and the relation between automaticity on one hand, and control and attention on the other, is further investigated by Wayne Wu in "Automaticity, Control and Attention in Skill." Skill emerges from a shifting balance between automaticity and 
control over time. But how can a skillful performance be both automatic and controlled? As Wu teaches us, a rich psychological literature has assumed an overly simple connection between automaticity and control, assuming that performance can be under one's control if and only if it is not automatic. This connection, so understood, stands in the way of a full understanding of skillful performance as both automatic and controlled. Wu argues that in order to understand this feature of skillful performance, we ought to think of the structure of intentional agency as the locus where automaticity and control merge. While it is true that the same process cannot be wholly automatic and at the same time wholly controlled, certain features of the process might be automatic while other features of the same process can be under one's control. In particular, Wu proposes we individuate the properties of an intentional action that are under agentive control as those that are the result of the agent's executive intention to perform the action in this or that way. On the other hand, the properties of a process that are not under agential control are those that are not the result of the agent's executive intention. Wu argues that this way of retaining a strong division between automaticity and control also allows one to accommodate the observed gradualism in automaticity and control manifested in skill learning, for the set of properties that are automatic or controlled changes over time and so does the tuning of the specific action properties. Finally, Wu shows us how to apply this theoretical framework to a case study - the research on overt attention in batting sports.

The role of intentions and intentionality in skillful performance has long motivated intellectualist theories about know-how (Pavese 2013, 2018, 2020; Stanley and Krakauer 2013). If manifestations of knowing-how are intentional, because intentional action seems to require knowing what to do to initiate the action, intellectualists have argued that propositional knowledge about how to perform an action is central to skillful action. On this basis, Stanley and Krakauer (2013) argued that motor skill depends on knowledge of facts, forwarding a challenge to the standard interpretation of amnesiac cases, such as patient HM, that have led to the familiar dichotomy between procedural and declarative knowledge in psychology. In "Automatizing Knowledge: Confusion Over What Cognitive Neuroscience Tells Us About Intellectualism," John W. Krakauer recapitulates his argument to the effect that neuroscientific evidence suggesting that procedural knowledge and declarative knowledge dissociate has been misinterpreted as evidence for an anti-intellectualist position. The right understanding of $\mathrm{HM}$ and other amnesiac cases, Krakauer argues, supports a version of intellectualism about know-how. Krakauer goes on to respond to some critiques of this earlier position. As Krakauer himself acknowledges, something was missing from Stanley and Krakauer's (2013) version of intellectualism about know-how and skill-i.e., the role of a distinctively motor and procedural representation in the explanation of know-how and skill (see also Pavese, Chapter 18 in this volume). Krakauer proposes that we integrate that account of skillful action by appealing to what he calls "control policies" (cf. Shmuelof et al. 2012; Haith and Krakauer 2013, 2018). As he understands them, control policies are "rules that automatize and are cached with practice" and which are no longer propositional once cached. For example, the policy for mirror drawing is to go left rather than right after making a leftward error; with practice this policy gets cached, which is why it does not have to be explicitly remembered by HM.

The role of procedural and practical representation in intellectualist theories about knowhow and skills is discussed in the next chapter, "Practical Representation." Carlotta Pavese elucidates the notion of a practical mode of presentation, first introduced by intellectualist theories of know-how, by comparing it to more familiar kinds of modes of presentation — perceptual and conceptual modes of presentation. By looking at psychological theories of motor control, Pavese forwards an account of the sort of motor and procedural representations that are posited 
by those theories and, against a widespread skepticism about the representational status of motor representation, provides a novel argument for thinking that motor representations are bona fide representations, in that they are assessable for accuracy and inaccuracy as they succeed or fail to accurately represent the intended target of the motor task. In the second half of the chapter, Pavese explores the theoretical need for practical concepts - or practical ways of thinking- that often make appearances in the intellectualist theories of know-how (Stanley and Williamson 2001; Pavese 2015), in order to account for a distinctively productive kind of reasoning - the capacity for which seems to be lost in motor deficits such as ideo-motor apraxia (Pacherie 2006; Pavese forthcoming). As she argues, far from being an unwelcome commitment of intellectualist theories of know-how, practical representation (both conceptual practical representation and non-conceptual practical representation) ought to play a central role in any theory of skill, whether or not intellectualist, that takes into serious account psychological and neuroscientific evidence.

In the next chapter, “The Nature of Skill: Functions and Control Structures," Ellen Fridland introduces a functional view of skill, where skills are to be understood as functions from intentions to actions that are implemented by a variety of control structures, which have been learned through practice. Fridland argues that this way of conceiving of skill incorporates the strengths and avoids the weaknesses of extant versions of intellectualism and anti-intellectualism about know-how. For Fridland, control structures are responsible for the flexible modification, adaptation, and adjustment of goal-directed action. Further, on her account, control structures are hierarchically organized on at least three levels: strategic, which includes practical planning and knowledge in action; attention, which selects perceptual information in an intention-sensitive way and integrates that information with online motor representations; and, motor, which involves motor representations that have been diachronically shaped through deliberate practice and which are, themselves, means-ends coherent with goal contents. In this way, Fridland maintains that motor representations are intelligent in several ways: in their capacity to adjust and adapt online to an unfolding action environment, in virtue of their learning history, and also because of their connection to states or structures of strategic control.

Further fleshing out how we ought to understand the intelligence of motor control, Myrto Mylopoulos, in "The Intelligence of Motor Control," argues that motor representations are intelligent not merely derivatively, as a result of their connection to intentions, but in their own right. To establish this position, Mylopoulos begins by introducing the puzzle of skilled action - a version of which we have seen appear in Wu's chapter: How can skilled action display robust intelligence despite being largely governed by motor control processes that are often characterized as brute, reflex-like, automatic, and paradigmatically unintelligent? For Mylopoulos, intelligence is cashed out in terms of flexibility and, thus, her challenge is to show that motor representations of the kind involved in skilled action are flexible in the relevant ways. To establish this, Mylopoulos argues for a hybrid view of skilled action, which acknowledges the role of intentions and propositional knowledge but also holds that motor representations are themselves intelligent in virtue of their temporal and functional organization. According to Mylopoulos, motor learning is a process that involves both refining the structure of a motor program but also fine-tuning the parameterization of that program. Accordingly, Mylopoulos locates the difference between the expert and novice in the complexity of their respective motor representations (see Pavese, Chapter 18 in this volume). As such, Mylopoulos's solution to the puzzle of skilled action involves elucidating the complex structure of motor representations in order to show that construing them as unintelligent is mistaken.

The final chapter of this part, "The Targets of Skill, and Their Importance," discusses a crucial methodological question that arises when studying skilled performance: What is this something 
that one is skilled at? Joshua Shepherd points out that skill essentially involves an agent's being excellent in some way: the skilled agent is skilled at something. This is the question of the "target of skills." According to Shepherd, one ought to be pluralist about the target of skills: agents display skill at actions, at games, and at a wide range of practices and activities. And this sort of pluralism about the target correspondingly motivates a sort of pluralism about skills, for it suggests that skills display variable structure, depending upon the target.

\section{I.4 Skill in perception, imagination, and emotion}

The next section of the Handbook is devoted to chapters that explore the connections between skill and perception, imagination and emotion. When it comes to phenomena like perception, especially visual perception, the connection to bodily skill has been forwarded as central in debates concerning embodied and enactive perception. For instance, as Siegel discusses below, Merleau-Ponty $(2013 / 1945)$ made the connection to bodily action central to his theory of visual perception. Also, famously, J. J. Gibson (2014/1979) argued that perception involved perception not only of colors or static properties but direct sensitivity to affordances or possibilities for action. Importantly, affordances are relational properties, which depend on the kinds of actions or skills that an agent could perform in the perceived environment. More recently, Kevin O'Regan and Alva Noë (O'Regan and Noë 2001; Noë 2004) have argued that perceptual experience is constituted in part by an agent's know-how. More specifically, they argue that what one sees depends on one's embodied knowledge of sensorimotor contingencies or, put another way, perception depends on sensorimotor skills. In contrast, connections between skill and imagination and skill and emotion, though implicit in some discussions, are still nascent but rich areas of philosophical inquiry.

Taking up the connection between action and perception, we begin with a chapter by Emily S. Cross. Cross provides us with a terrific overview of how the development and possession of embodied expertise affects action observation in her chapter, "Embodying Expertise as a Performer and Perceiver: Insights from the Arts and Robotics." Cross begins with a brief overview of the history of thought - philosophical, psychological, and neuroscientific — as it pertains to the connections, or lack thereof, between perception and action. She goes on to review key empirical studies in the domain of the performing arts, which demonstrate a robust relationship between the possession of embodied expertise, both longstanding and de novo, and the perception of action in that domain. That is, empirical research seems to indicate that the better one is at performing an action, the more one simulates that action when observing it. Cross goes on to review studies relating embodied expertise to aesthetic and affective experience and also to possible applications of this knowledge to social robotics, where understanding how humans relate to the actions of others may be crucial for developing well-calibrated, artificial, social agents. Part of the utility of Cross's chapter is its evenhandedness in both presenting research that robustly supports a simulation theory of action and perception and also highlighting various studies that complicate a straightforward or linear relationship between greater amounts of embodied expertise and greater engagement of sensorimotor cortices, greater aesthetic enjoyment, and even greater interpersonal rapport.

Working in a similar domain, Corrado Sinigaglia and Stephen A. Butterfill build out a theoretical framework for understanding the evidence that Cross introduces above by offering a substantive explanation of the connection between skill and observational knowledge. In "Motor Representation and Knowledge of Skilled Action," Sinigaglia and Butterfill begin by reviewing empirical evidence of increased skill or expertise leading to increased knowledge or accuracy in predicting the outcomes of observed actions within the domain of expertise. 
Sinigaglia and Butterfill go on to ask why developing motor skill should provide agents with the ability to acquire observational knowledge concerning that skill. They answer that it is because both performing motor skill and observing skill involve a common element: namely, a motor representation. That is, they claim that the same motor representation is involved in both guiding action and observing someone perform that same action.

Next, Sinigaglia and Butterfill go on to consider an objection concerning the proposal that motor representations play this dual role. The objection runs that representations can only have one direction of fit, but the role suggested above to motor representations has two. Sinigaglia and Butterfill respond to this potential objection by claiming that motor representations can have both a control and epistemic function relative to a system. As such, relative to one system, the motor representation can have a control function but, relative to another system, that same representation can take on an epistemic function. Sinigaglia and Butterfill end by considering a further potential issue with their view: the problem of how the content of motor representations can interface directly with that of personal-level epistemic states. They offer four proposals for how one might solve the interface problem that comes up at this juncture and go on to suggest empirical avenues to pursue in order to make progress on determining which of those solutions is true.

Moving from the connection between embodied expertises and action observation to questions about how skill might influence or constitute the processes of visual perception, we turn to Susanna Siegel's chapter, "Skill and Expertise in Perception." In order to understand how skill or expertise might be related to perception, Siegel proposes we work with a broad notion of skill, where exercises of skill are not necessarily instances of intentional action, and she further focuses on conscious perceptual experience. Siegel discusses three main ways in which perceptual experiences might be thought to manifest a subject's skills in this broader sense. According to the first, perceptual experience consists in, or necessarily engages motor skills. This idea traces back to the philosophy of Merleau-Ponty (2013/1945), according to whom in paradigmatic cases of perception, the flow of information is inseparable from the way a perceiver moves through a perceptual scene. Siegel reviews how this model of perceptual experience as necessarily engaging motor skills has inspired contemporary thinkers such as Noë (2004) and Kelly (2005) to generalize it to cases of apparently static perception. According to one such proposal, static perception also engages the body, for it involves the bodily activity of finding optimal viewpoints. Siegel then turns to the second way in which perception might be thought to manifest skills-i.e., by involving recognitional capacities. Siegel points out that one way to articulate this idea is to embrace Lewis's (1990) ability hypothesis: knowing what something looks like amounts to possessing certain sorts of practical abilities or know-how.

Finally, the third way in which perceptual experiences involve skills is by patterns of attention being affected by the skill and expertise that we have. As Siegel notes, distributions of attention might depend on scientific expertise: for example, faced with the same sequence of X-ray images, a radiologist and a novice will parse each image differently. Perceptual learning might also depend on improved acuity in categorization. For example, gaining practice and expertise in music can improve the ability to find the beat in a piece of music and keep track of it. Finally, cultural embeddings can shape our perceptual experience and attention. Here, Siegel reviews some important work providing experimental evidence that cultural stereotype can direct attention toward stereotype-congruent information, and away from stereotype-incongruent information (Eberhardt et al. 2004) and that the extent of gaze-following behavior can be sometimes sensitive to race and social power (Adams and Kveraga 2015). 
Extending considerations of perceptual learning to perceptual expertise, Dustin Stokes and Bence Nanay's chapter, "Perceptual Skills," starts out by offering a way of distinguishing between properly perceptual and post-perceptual or cognitive skills. Stokes and Nanay go on to argue that cases of perceptual expertise, such as those found in expert birdwatchers or fingerprint examiners, involve properly perceptual skills. That is, these cases of expert perception involve skills of the perceptual system. Stokes and Nanay go on to consider the case of picture perception and likewise conclude that such perception involves perceptual skill. Importantly, what this shows is that possession of different visual skills will result in differences in the phenomenology of viewing the same picture. They end their chapter by isolating what they call "mechanisms" of perceptual skill: perceptual attention and mental imagery. In both cases, what's most central to skill is that the development of both perceptual attention and mental imagery are sensitive to top-down information and are thus robustly connected to the semantic and epistemic states of agents. Because of this, at least some perceptual skills, Stokes and Nanay argue, are properly attributable to the agent. Stokes and Nanay conclude by highlighting the fact that far from being some peripheral or niche area of theoretical work, perceptual skill is central to our full understanding of perception in general.

The last chapter in this part to address skills of perception or, more particularly, skills of the visual system, is Keota Fields' ambitious chapter, "Skill,Visual Prejudice, and Know-How." Fields contends that the visual system learns to see in roughly the same way as a person learns to swim. More specifically, the suggestion Fields endorses is to treat visual perception, generally, as skilled Bayesian inference. Treating vision as a skill, Fields maintains, does justice to the central commitments of a constructivist model of visual perception and, further, explains in a fairly straightforward manner the mechanisms of cognitive penetration.

Using this approach to visual perception, Fields goes on to argue that at least some cases of visual prejudice offer a counterexample to the often assumed identity between skill and knowhow. This is because visual prejudice, as Fields argues, is an instance of skilled visual perception but does not manifest knowledge of facts. Using the example of implicit-bias infused visual perception, Fields argues that such an episode is an instance of skilled seeing because the episode is characterized by features that are diagnostic of skill: automaticity, diachronic refinement (i.e., improvement through training), intelligent task sensitivity, selective attention, and control. Moreover, Fields argues that a proper construal of control, for which Fields reaches for Wayne Wu's account (see Wu, Chapter 16 in this volume), shows that episodes of visual prejudice are in fact intentional. However, since cases of visual prejudice do not manifest knowledge of facts, these skilled seeings cannot be instances of know-how. In this way, Fields argues that skills and knowledge-how cannot be identical.

Moving from perception to imagination, Amy Kind in "The Skill of Imagination," lays out the case for thinking of imagination as a type of skill. Kind begins by extracting from the literature three central features of skill: Skill (1) can be done more or less well; (2) is under one's intentional control; and (3) can be improved via practice/training. These conditions serve as a general framework for categorization rather than as necessary and sufficient conditions of skill. Kind goes on to argue that at least certain types of imagination, namely sensory and experiential imagining, meet these conditions. Thus, she concludes, sensory and experiential imagining should be classified as skills. Kind ends by considering various objections to classifying imagination as a skill: what she calls the Socratic objection (i.e., where are the skilled imaginers?), the nativist objection (i.e., imagination cannot be improved via training), and the no feedback objection (i.e., what kind of feedback could possibly be used to improve imagination?). By reviewing several lovely cases of imagination's role in invention, art, and empirical study, Kind 
responds to objections and ends by noting the importance of thinking of imagination as a skill. She claims that not only can this conception of imagination help rein in philosophers who draw metaphysical conclusions from their stunted abilities at imagination but it can perhaps also entice us to train skills of imagination through childhood education and beyond.

In the final chapter of Part IV,"Emotion Recognition as a Social Skill," Gen Eickers and Jesse Prinz argue that emotional recognition, which is often thought of as static, passive, and innate is actually best construed as a type of skill. Eickers and Prinz not only maintain that emotional recognition is a skill, but suggest that emotions themselves may actually be skills as well. Like Kind and Fields above, Eickers and Prinz begin by extracting from the literature several central characteristics of skill. For them, the most notable features of skills are their improvability, practicality, and flexibility. Eickers and Prinz then go on to show that emotional recognition is characterized by these properties and, further, that these properties of emotional recognition are often overlooked in one way or another by extant theories of social cognition: Evolved Expression Recognition, Theory Theory, Simulation Theory, and Direct Perception. Eickers and Prinz end by forwarding a positive conception of emotional recognition in terms of the skilled recognition of emotional scripts. On this way of understanding emotions, they are sequences of subevents "that include: causes, beliefs, feelings, physiological changes, desires, overt actions, and vocal and facial expressions." They are called scripts because they are in some ways like a playwright's scripts but, unlike a playwright's script, they are flexible and embody norms that are both statistical and philosophical. This view entails that recognizing emotions requires fluency with these emotional scripts, which are variable, contextual, intelligent, embodied, and practical.

\section{I.5 Skill, language, and social cognition}

Human skills can manifest socially: in joint and coordinated action generally and in linguistic and communicative skill specifically. Part V includes chapters that look at skills in language and social cognition.

The section starts with the chapter "Skill and Expertise in Joint Action" by James Strachan, Günther Knoblich, and Natalie Sebanz, which focuses on the question: What are the mechanisms that allow people to perform skilled joint actions playing in a band, in a sports team, or in a collective dance? Investigating the mechanisms whereby people come to be able to perform joint actions skilfully raises the question of how coordination can be achieved in the course of cooperative and competitive interaction. In addressing this question, this chapter draws on studies from a wide range of skilled joint actions, including music, sports, and dance, as well as on more basic coordination tasks designed to investigate fundamental mechanisms of coordination. The chapter describes empirical evidence for three main coordination mechanisms: strategic action modulations, joint action planning and monitoring, and action prediction. Evidence for strategic action modulations comes from studies in joint improvisation, where it was found that people tend to make themselves more predictable by systematically modulating the velocity profile of their movements in order to achieve synchrony with their partner, by increasing the amount of ancillary movements, which can also play the collaborative function to adapt to adverse conditions, and by controlling, and in some cases resisting, entrainment, the process whereby two or more individuals producing regular patterns of behavior fall into the same rhythm. The chapter details the importance of expert action perception for prediction (see Sinigaglia and Butterfill, Chapter 23 in this volume)-i.e., for coming to be able to read and anticipate the actions of others; the most recent studies on action perception showing the connection between motor expertise and the sophistication of one's ability to perceive features of motor actions; and the mechanics of how people represent others' affordances and limitations as well as the extent to 
which representation of the others' action is helpful or detrimental to joint action. As a joint action requires the input of more than one individual to achieve a joint goal, it is not sufficient to represent what another could do. It is also necessary to monitor what that person does, particularly with regard to any errors made, so that one can adjust one's own behavior or prepare for any costs incurred. After introducing the most recent research on collaborative action, the chapter ends by discussing joint action in competitive interactions. The authors show that perhaps surprisingly, competition involves some of the same coordination mechanisms described for cooperative joint action, such as strategic modulations of action, action prediction, monitoring, and co-representation.

Joint action also raises questions for phenomenological concepts of expert performance on which an expert operates completely on the pre-reflective level of experience. As we have seen by looking at Dreyfus' conception of skillful action, on some phenomenological conceptions of expert performance, the expert operates completely on the pre-reflective (i.e., tacit, nonobservational, non-objectifying) level of experience (Dreyfus 1997, 2002, 2005). In "Self- and Other-Awareness in Joint Expert Performance," Shaun Gallagher and Jesús Ilundáin-Agurruza critically assess this view by looking at the role of self-awareness and the awareness of others during joint actions. They start by introducing a theoretical debate about the nature and the extent of individual self-awareness during experts' performance and by reviewing the evidence motivating Shusterman's (2008) and Montero's (2016) “trained awareness model," according to which expert performance requires a particular type of trained awareness. Then Gallagher and Ilundáin-Agurruza move to examining questions about the role of self-awareness of others in team and collaborative performances. Just like in the case of individual performance, the phenomenological tradition features accounts suggesting that reflection also interrupts team or cooperative performance, and that working together best remains pre-reflective (e.g., Schutz 1976). In order to assess this position, Gallagher and Ilundáin-Agurruza review a detailed study of expert musical performance by Høffding (2015). In his study of the Danish String Quartet, Høffding conducted phenomenological interviews and focused on the precise experiences the musicians had while playing their best. It turns out that each member of the quartet had different experiences while playing but all of them reported they could be thinking of or experiencing different things. As they point out, these studies might show that Dreyfus was wrong to think that any kind of reflective thinking necessarily interrupts performance. On the other hand, some of these studies also suggest that explicit consciousness of the other players, or an explicit attending to one's actions might not always be needed to make the performance work. At least in some cases, in line with Dreyfus' analysis and against the trained awareness model, the real work seems to be done in a manner that involves skillful automaticity or a minimally pre-reflective level. They conclude that the contrasting positions represented by Dreyfus and Shusterman might both be off the mark, and they advocate an alternative pluralist model that helps refine the analysis of self- and other-awareness in expert performance.

Among our distinctively and perhaps uniquely human skills are the uses of a range of sophisticated motor tools and cognitive and communicative tools. Are these human-specific skills biologically inherited, or are they learned? These questions are investigated by Antonella Tramacere and Richard Moore in "The Evolution of Skilled Imitative learning: A Social Attention Hypothesis." Tramacere and Moore discuss the hypothesis that these uniquely human skills arise on the back of our possession of a more fundamental skill: imitation. Imitation is a form of action copying in which an agent is concerned to replicate the precise strategy of an observed demonstration. Tramacere and Moore review the ongoing debate about the origins of human imitation. According to one influential view, defended by Michael Arbib (2005, 2012, 2017) among others, the Mirror Neuron System in humans is a candidate for being the neural 
substrate of action copying behavior. As such there is an important innate component to imitation that is the result of biological evolution. Against this view, a group of psychologists led by Celia Heyes (2018) have argued that imitation is a product of cultural and not biological evolution. As an alternative to both nativism and non-nativism about imitation, Tramacere and Moore propose a third account of the origins of imitation, that borrows elements from both the nativist and non-nativist hypotheses while offering a parsimonious explanation of the cognitive and neurobiological differences between humans and other species.

As Tramacere and Moore make clear, imitation is central not only to the mastery of manual tools but also to the development of another distinctively human skill: language. This brings us to the other main topic of this section: linguistic competence and its nature, which is discussed in two chapters of this Handbook. In "Semantic Competence," Diego Marconi outlines a history of the debates concerning the ability to understand sentences of a natural language, ranging from Chomsky's $(1965,1985)$ discussion of linguistic competence and his critique of philosophical semantics to the recent debate about simulation theories. For Chomsky, linguistic competence was a sort of knowledge underlying our syntactic competence that could not be simply identified with a practical ability but that was not straightforwardly to be identified to propositional knowledge either-in the standard epistemological sense of knowledge available at the personal level and that requires justification. Marconi reviews Chomsky's criticism of philosophical semantics, as well as the main philosophically originated semantic theories (Montague's and Davidson's). Both Davidson (1967) and Montague (see Thomason 1974) agreed in identifying the aim of semantics with providing a theory of how the meanings of sentences depended on the meaning of the composing words and neither intended their theories as models of human semantic competence. Neither projects, nor their more recent cognitive developments, involved attention to psychological or neurophysiological plausibility of the semantic categories and processes that they posited. Marconi explains that this sort of criticism, raised prominently by Partee (1981) and others, gave rise to diverging responses. Some, like Jackendoff (1992) and Johnson-Laird (1983) opted for a form of internalism about the meaning of words according to which words got their meanings not by being suitably related to the environment but by being connected with internal representations and processes. By contrast, non-cognitive externalists such as Putnam (1975) thought that the meaning of natural kind words was fixed by objective causal connections with objects and properties in the world. Finally, cognitive externalists such as Marconi (1997) maintained that lexical competence was partly based on perceptual and motor connections with the world out there. According to this view, knowing the meaning of words such as "pear" and "bed" involves the ability to perceptually recognize pears and beds as well as the ability to appropriately respond to commands involving such things. This sort of position was motivated by debates within and about Artificial Intelligence which emphasized the role of perception and motor action in the exercise of semantic competence as well as by neuroscientific results that appeared to prove involvement of motor and perceptual brain areas in comprehension and, more generally, in language processing. Such research generated a partly new paradigm, which made language understanding consist in such perceptual and motor activations-i.e., the prominent simulationist paradigm (Barsalou 1999; Gallese and Lakoff 2005 , among others). Marconi ends the chapter by discussing this radical position and highlights some of its difficulties.

In "Pragmatic Competence," Filippo Domaneschi and Valentina Bambini give an overview of the field of pragmatics, which studies language in contexts. They start from reviewing Grice's $(1957,1975)$ understanding of meaning in terms of a speaker's intentions and his distinction between what a speaker says by using a sentence and what the speaker intends to communicate. According to a Gricean analysis of the notion of meaning in terms of speakers' intentions, 
what a speaker means to communicate does not need to coincide with what she explicitly says. The Gricean analysis has led contemporary linguists and philosophers to a mainstream view of pragmatics as the study of the speaker's meaning and of the inferential processes of reconstruction of communicative intentions. Domaneschi and Bambini carefully investigate the reason why only in the 1980s did pragmatics become the subject of cognitive studies. Until then, it was conceived as having to do with the linguistic performance, rather than linguistic competence, and as such it was excluded from linguistic investigations having to do with the level of competence, pertaining to syntax. Fodor's (1983) modular theory of mind refused to view pragmatic processing as governed by a specific and independently analyzable module in the way classic Chomskyan competence (Chomsky 1957, 1980) was. And the Gricean roots of pragmatic studies contributed to pragmatic processing being viewed in strict relation with the ability of attributing mental states to others and hence largely tied with general and not modulespecific mind reading abilities-i.e., with the theory of mind (ToM). Cognitive pragmatics arose as a revision of the Fodorian notion of module in order to account for pragmatic processing within the modular framework. Domaneschi and Bambini survey the most recent research in Experimental Pragmatics - where pragmatic phenomena are investigated via behavioral and neurolinguistic methods - that offer solid evidence in support of the thesis that pragmatic competence is not limited to the ability to understand speaker's intentions and, hence, pragmatic competence cannot be reduced to a ToM ability. They review experimental work on the cognitive mechanisms governing processing of presupposition, conversational mechanisms such as turn-taking, understanding of metaphors, suggesting instead that pragmatic competence has specific characterization in terms of developmental trajectories, patterns of decay, and neural substrates - a characterization that is distinct and independent of a characterization in terms of mind reading abilities.

\section{I.6 Skill and expertise in normative philosophy}

In the final part of the Handbook, six chapters address questions of skill and expertise in normative philosophy. As will be familiar to the reader, virtue ethicists have often appealed to skill in order to articulate the nature of moral cognition and judgment. That is, morality, for the virtue ethicist, amounts to a kind of expertise. However, there remain crucial questions about whether moral judgment and behavior is best construed as a kind of skill (Annas 1995, 2001; Stichter 2018) and whether wisdom can be construed as a sort of moral expertise (Driver 2013, 2015), about what kind of thing such a skill could be, whether morality might require skill even if morality itself is not a skill, and, importantly, how the practical demands of morality may require the development of moral perception or other perceptual and emotional skills. Questions of education, persuasion, and implicit bias and stereotype threat also arise in connection to these considerations, since it remains an open question whether and how we might be able to actually change not only our beliefs and attitudes but also our automatic, immediate, reactions, responses, perceptions, or associations through training, argument, or the development of virtue (Gendler 2011; Saul 2013).

The first chapter in PartVI is Julia Driver's, "Moral Expertise," where the author provides a superb overview of the major debates in the literature concerning moral expertise. She begins by comparing moral expertise to more familiar types of expertise, like those in the domains of science or mathematics. An important distinction between kinds of expertise that Driver highlights concerns the fact that moral expertise is normative and not merely descriptive. It is not only about how the world is but about how it ought to be. And also, perhaps importantly, about how one ought to be/act oneself. 
Driver goes on to discuss in some detail the distinction between moral knowledge and moral understanding, and to consider which may be required for moral expertise. Driver herself thinks there are various ways to gain moral expertise, some of which do not require a full, systematic or articulable understanding of morality. In fact, moral expertise, in some cases, may simply amount to having an ability to make reliable judgments about moral matters. Driver ends by examining the role of empirical facts and moral action in moral expertise. In contrast to others in this section (e.g., Stichter and Bashour), Driver maintains that the way in which moral expertise is acquired is merely a contingent fact about what moral expertise is. As such, she holds that analysis of the normal development of moral expertise, even if in actual fact for humans it requires practice, does not tell us anything substantive about the nature of that expertise.

Moving from moral expertise to political expertise, Alexander A. Guerrero provides a contextualist, functionalist account of the normative political expert and expert political actor in "A Theory of Political Expertise." First, Guerrero distinguishes between, on the one hand, what he calls the expert political analyst (someone who has extensive knowledge about political topics) and the exceptionally effective political actor (someone who is able to navigate political institutions effectively, regardless of moral outcome) and, on the other, the normative political expert (someone who knows what ought to be done) and expert political actor (someone who is particularly skillful in doing what ought to be done). It is the latter type of expertise that concerns Guerrero and that he considers to be the proper domain of political experts.

It is important to note that since Guerrero's account of political expertise is functionalist and contextualist, it requires asking both about the purposes or ends of the political agent but also recognizing that those ends or purposes are not universal but relative to context and role. Doing justice to the embedded and contextual nature of political expertise, Guerrero explores what it means to be a normative political expert and expert political actor specifically as an elected political representative. Guerrero argues that the proper end or purpose of the elected political representative is to achieve the legitimating purposes of political institutions. These purposes include: preventing domination and harm; minority rights and justice; working together under conditions of disagreement and distrust; information management and use; respecting and promoting equality; respecting and promoting autonomy; and promoting welfare. He goes on to explain that achieving these legitimating purposes requires more than moral expertise but also a variety of epistemic virtues, including epistemic humility and open-mindedness. It will also involve disagreement navigation, which requires knowing which paths are feasible and available under conditions of disagreement and also the skills of compromise, conflict resolution, mediation, and the need to override dissenting opinion. For political expertise of the kind characteristic of the elected political representative, one should also exhibit the moral virtues of ethical leadership in addition to being a relatively expert moral analyst, so as to be able to make appropriate moral judgments in situations of complexity. Together, these conditions combine to form a theoretical or philosophical proposal for what expertise for the elected political representative consists in. Guerrero insists, however, that such a framework is not the end of the project but should be tested through modeling and empirical study.

Expanding what it means to possess the virtue of justice from the political, social or moral domain to the individual, Paul Bloomfield develops a historically grounded account of justice as a personal, moral and intellectual virtue in "Skills of Justice." The skills of justice apply broadly, Bloomfield argues, because they concern, very generally, making appropriate, measured judgments or just assessments. This way of thinking of justice, locates justice not only in the moral domain but also squarely in the epistemological domain, as a good moral, political or social judgment requires not only moral fairness but also epistemic accuracy. Moreover, the skills of justice apply not only interpersonally but intrapersonally, since making 
morally fair and epistemically accurate judgments concerns not only how we judge others but also how we judge ourselves. Strikingly, Bloomfield sees the skills of justice as applying even beyond the moral domain, since even in making e.g., scientific judgments, one has to judge judiciously, putting like with like and doing justice to relevant differences. In this way, the virtue of justice, as Bloomfield conceives of it, is an individual, intellectual virtue that applies across the board.

Moving from moral judgment to its connection with moral or virtuous behavior, Bana Bashour, in her chapter, "Why Moral Philosophers Are Not the Most Virtuous People," provides us with an account of moral behavior that is grounded in skill. Bashour begins by providing examples that highlight the double-dissociation between moral judgment and virtuous behavior: on the one hand, an example of a philosopher who reliably makes strong moral arguments but often acts selfishly and, on the other, Huck Finn who makes the wrong moral judgment but still acts virtuously.

Bashour argues that moral judgment and moral action come apart because moral or virtuous behavior is a kind of skill and moral judgment is either not a skill at all or relies on a distinct set of skills. Bashour goes on to review the main intellectualist and anti-intellectualist positions concerning skill in general, as well as virtue as skill, in particular and argues that both positions have shortcomings. Bashour recommends pursuing instead the blended account that Ellen Fridland develops (see Chapter 19 in this volume) where skill involves three levels of control. Bashour ends with two striking and timely examples of virtuous behavior where she describes how control at different levels is relevant for moral action. Importantly, Bashour emphasizes that even in cases of virtuous action, motor control is substantively implicated in moral behavior.

From an analysis of virtuous, skilled action to an account of how virtue might be acquired and improved, Matt Stichter, in his chapter, "Virtue as Skill, Self-Regulation and Social Psychology," develops a skill-based account of moral virtue in order to respond to situationist critiques of virtue ethics. Notably, the skill as virtue account that Stichter develops is heavily informed by empirical studies in psychology and he combines the lessons of those studies in order to recommend a way forward for moral education.

Stichter begins by claiming that skill is essentially a sophisticated form of self-regulation. As such, understanding skill requires understanding the literature on self-regulation. Critically, we should begin by differentiating between goal setting and goal striving. That is, differentiating between the process of setting an intention, even a complex one with subgoals, and the process of striving to attain that intention via planning and action. On Stichter's view, goal striving has often been overlooked by the literature on virtue, which emphasizes making the right judgment or setting the right intention but not developing the proper skills for achieving the ends to which one has already committed.

In contrast, a view informed by empirical psychology allows us to home in on effective strategies for reaching goals, such as, for example, implementation intentions. Such if-then intentions allow agents to deliberately set situation-specific strategies that can be used automatically in specified circumstances. Moreover, deliberate practice of specific strategies can provide further refinement of the means or skills necessary to reach one's already set goals. This is especially important, Stichter argues, because much of the actual literature in social psychology (e.g., the bystander effect) shows deficits in moral behavior can be attributed not to a lack of good intentions but to a lack in competencies and the related beliefs concerning one's self-efficacy. As such, Stichter argues that moral education should be concerned not only with setting the right intentions or making the correct judgment concerning morality but with developing the often complex skills required for attaining our moral goals. It is through such skill-based education that stable virtue can be developed and that situation-specific forces may be overcome. 
Pursuing a similar approach to Stichter, Michael Brownstein, in "De-biasing, Skill, and Intergroup Virtue," consults the literature in empirical psychology in order to develop an account of the skills involved in de-biasing others, that is, in diminishing the prejudices, stereotypes, and biases that others possess. Brownstein begins by noting that changing people's opinions, attitudes, and beliefs is at the heart of a healthy democracy but goes on to review some depressing results concerning the actual success of changing others' minds. Brownstein then goes on to highlight which skills, strategies, knowledge, and abilities are likely involved in successful de-biasing. Importantly, Brownstein thinks of the power to de-bias as a skill because it is something one can learn and improve over time with practice. So, what does the skill of de-biasing require? Unfortunately for the philosopher, Brownstein is pretty pessimistic about the power of argument or "going factual" to change people's attitudes. Instead, Brownstein suggests that changing the perception of norms is at the heart of de-biasing because people are not only motivated to conform with norms but they are also concerned about the rewards and punishments associated with them. In order to change the perception of norms, Brownstein suggests that de-biasers do not directly try to change the attitudes that others have toward norms but, rather, the perception of what other people believe and feel. Skill in de-biasing then, may involve becoming a social referent, that is, a person with particular influence over other people's perception of norms due to one's e.g., status or prestige. Social referents can model virtuous norms, such as tolerance, compassion, open-mindedness, etc. and in so doing change what others think is acceptable, thereby also changing others' motivation to conform with these new virtuous norms.

\section{Note}

1 The order of the authors is alphabetical.

\section{References}

Adams, R., and Kveraga, K. (2015) "SocialVision: Functional Forecasting and the Integration of Compound Social Cues," Review of Philosophy and Psychology 6: 591-610.

Annas, J. (1995) "Virtue as a Skill," International Journal of Philosophical Studies 3: 227-43.

_ (2001) "Moral Knowledge as Practical Knowledge," in E. F. Paul, F. D. Miller, and J. Paul (eds.) Moral Knowledge, 236-56, Cambridge: Cambridge University Press.

- (2011) "Practical Expertise," in J. Bengson and M. Moffett (eds.) Knowing How: Essays on Knowledge, Mind, and Action, 101-12, Oxford: Oxford University Press.

Anscombe, G. E. M. (1957) Intention. Basil Blackwell: England.

Arbib, M. A. (2005) "From Monkey-Like Action Recognition to Human Language: An Evolutionary Framework for Neurolinguistics," Behavioral and Brain Sciences 28: 105-24.

_ (2012) “Tool Use and Constructions,” Behavioral and Brain Sciences 35: 218-19.

- (2017) "Toward the Language-Ready Brain: Biological Evolution and Primate Comparisons," Psychonomic Bulletin \& Review 24: 142-50.

Barsalou, L. (1999) "Perceptual Symbol Systems," Behavioral and Brain Sciences 22: 577-660.

Beddor, B., and Pavese, C. (2018) "Modal Virtue Epistemology," Philosophy and Phenomenological Research, doi: $10.1111 /$ phpr.12562. - (2020) "Skill as Knowledge," manuscript.

Bengson, J., and Moffett, M. (2011) “Nonpropositional Intellectualism,” in J. Bengson and M. Moffett (eds.) Knowing How: Essays on Knowledge, Mind, and Action, 161-95, Oxford: Oxford University Press.

Brogaard, B. (2009) "What Mary Did Yesterday: Reflections on Knowledge-Wh," Philosophy and Phenomenological Research 78: 439-67.

Buchanan, A. (2004) "Political Liberalism and Social Epistemology," Philosophy \& Public Affairs 32: 95-130. (2009) "Social Moral Epistemology and Public Policy," Journal of Applied Philosophy 19: 126-52. 
Carter, A., and Navarro, J. (2018) “The Defeasibility of Knowledge-How," Philosophy and Phenomenological Research 95: 662-85.

Carter, A., and Pritchard, D. (2015) “Knowledge-How and Epistemic Luck,” Noûs 49: 440-53.

Cath, Y. (2011) "Knowing How Without Knowing That," in J. Bengson and M. Moffett (eds.) Knowing How: Essays on Knowledge, Mind and Action, 136-60, Oxford: Oxford University Press.

_ (2013) "Regarding a Regress," Pacific Philosophical Quarterly 94: 358-88.

- (2015) "Revisionary Intellectualism and Gettier," Philosophical Studies 172: 7-27.

Chomsky, N. (1957) Syntactic Structures, The Hague: Mouton.

- (1965) Aspects of the Theory of Syntax, Cambridge, MA: MIT Press.

- (1980) Rules and Representations, New York: Columbia University Press.

- (1985) Knowledge of Language, New York: Praeger.

Coope, U. (forthcoming) "Aristotle on Productive Understanding and Completeness," in T. K. Johansen (ed.) Technê in Ancient Philosophy, Cambridge: Cambridge University Press.

Damasio, A. R. (1999) The Feeling of What Happens: Body and Emotion in the Making of Consciousness, New York: Houghton Mifflin Harcourt.

Davidson, D. (1967) “Truth and Meaning," Synthese 17: 304-23.

Devitt, M. (2011) "Methodology and the Nature of Knowing How," The Journal of Philosophy 108: 205-18.

Dreyfus, H. L. (1997) "Intuitive, Deliberative, and Calculative Models of Expert Performance," in C. Zsambok and G. Klein (eds.) Naturalistic Decision Making, 17-28, Mahwah, NJ: Lawrence Erlbaum. (2000) "A Merleau-Pontian Critique of Husserl's and Searle's Representationalist Accounts of Action," Proceedings of the Aristotelian Society 100: 287-302.

_ (2001) “The Primacy of Phenomenology over Logical Analysis," Philosophical Topics 27: 3-24.

_ (2002) "Intelligence Without Representation: Merleau-Ponty's Critique of Mental Representation," Phenomenology and the Cognitive Sciences 1: 367-83.

(2005) "Overcoming the Myth of the Mental: How Philosophers Can Profit from the Phenomenology of Everyday Expertise," Proceedings and Addresses of the American Philosophical Association 79: 47-65.

— (2007) "Response to McDowell," Inquiry 50: 371-7.

Driver,J. (2013) “Moral Expertise: Judgment, Practice, and Analysis,” Social Philosophy and Policy 30: 280-96. - (2015) "Virtue and Moral Deference," Etica \& Politica 17: 27-40.

Eberhardt, J. L., Goff, P. A., Purdie, V. J., and Davies, P. G. (2004) "Seeing Black: Race, Crime, and Visual Processing," Journal of Personality and Social Psychology 87: 876-93.

Fodor, J.A. (1983) The Modularity of Mind: An Essay on Faculty Psychology, Cambridge, MA: MIT Press.

Fridland, E. (2013) “Problems with Intellectualism," Philosophical Studies 165: 879-91.

_ (2014) “They’ve Lost Control: Reflections on Skill," Synthese 91: 2729-50.

_ (2017a) "Skill and Motor Control: Intelligence All the Way Down," Philosophical Studies 174: 1539-60.

_ (2017b) “Automatically Minded," Synthese 194: 4337-63.

Gallese, V., and Lakoff, G. (2005) "The Brain's Concepts: The Role of the Sensory-Motor System in Conceptual Knowledge," Cognitive Neuropsychology 21: 455-479.

Gendler, T. S. (2011) "On the Epistemic Costs of Implicit Bias," Philosophical Studies 156: 33-63.

Gibson,J.J.(2014/1979) The Ecological Approach toVisual Perception: ClassicEdition, New York: Psychology Press.

Goldman, A. (2001) "Experts: Which Ones Should You Trust?" Philosophy and Phenomenological Research 63: 85-109.

Grice, H. P. (1957) “Meaning,” The Philosophical Review 66: 377-88.

- (1975) "Logic and Conversation," in P. Cole and J. Morgan (eds.) Syntax and Semantics, Vol. 3, Speech Acts, New York: Academic Press.

Guerrero, A. (2016) "Living with Ignorance in a World of Experts," in R. Peels (ed.) Perspectives on Ignorance from Moral and Social Philosophy, New York: Routledge.

Haith, A. M., and Krakauer, J. W. (2013) "Model-Based and Model-Free Mechanisms of Human Motor Learning," Advances in Experimental Medicine and Biology, 782: 1-21. doi:10.1007/978-1-46145465-6_1.

_ (2018) “The Multiple Effects of Practice: Skill, Habit and Reduced Cognitive Load," Current Opinion in Behavioral Sciences 20: 196-201.

Heyes, C. (2018) Cognitive Gadgets: The Cultural Evolution of Thinking, Cambridge, MA: Harvard University Press.

Høffding, S. (2015) A Phenomenology of Expert Musicianship (PhD thesis), Department of Philosophy, University of Copenhagen, Copenhagen.

Hornsby, J. (2016) “Intending, Knowing How, Infinitives,” Canadian Journal of Philosophy 46: 1-17. 
Jackendoff, R. (1992) Languages of the Mind, Cambridge, MA: MIT Press.

Johansen, T. K. (2017) “Aristotle on the Logos of the Craftsman,” Phronesis 62: 97-135.

Johnson-Laird, P. (1983) Mental Models, Cambridge: Cambridge University Press.

Kelly, S. D. (2005) "Seeing Things in Merleau-Ponty," in T. Carman and M. Hansen (eds.) The Cambridge Companion to Merleau-Ponty, 74-110, Cambridge: Cambridge University Press

Lewis, D. (1990) "What Experience Teaches," in W. Lycan (ed.) Mind and Cognition, 499-519, New York: Blackwell.

Lorenz, H., and Morison, B. (2019) “Aristotle's Empiricist Theory of Doxastic Knowledge," Phronesis 64: 431-64.

Marconi, D. (1997) Lexical Competence, Cambridge, MA: MIT Press.

Marley-Payne, J. (2016) Action-First Attitudes (PhD thesis), Massachusetts Institute of Technology.

Merleau-Ponty, M. (2013/1945) Phenomenology of Perception, New York: Routledge.

Montero, B. (2016) Thought in Action: Expertise and the Conscious Mind, New York: Oxford University Press.

Noë, A. (2004) Action in Perception, Cambridge, MA: MIT Press.

— (2005) “Anti-Intellectualism," Analysis 65: 278-90.

O'Regan, J. K., and Noë, A. (2001) "A Sensorimotor Account of Vision and Visual Consciousness," Behavioral and Brain Sciences 24: 939-73.

Pacherie, E. (2006) “Towards a Dynamic Theory of Intentions," in S. Pockett, W. Banks, and S. Gallagher (eds.) Does Consciousness Cause Behavior? An Investigation of the Nature of Volition, 145-67, Cambridge, MA: MIT Press.

Partee, B. (1981) "Montague Grammar, Mental Representations and Reality," in S. Kanger and S. Öhman (eds.) Philosophy and Grammar, 59-78, Dordrecht: Reidel.

Pavese, C. (2013) The Unity and Scope of Knowledge (PhD thesis), Rutgers University.

- (2015) "Practical Senses," Philosophers' Imprint 15: 1-25.

_ (2017) "Know-How and Gradability," Philosophical Review 126: 345-83.

_ (2018) "Know How, Action, and Luck," Synthese, https://doi.org/10.1007/s11229-018-1823-7. - (2019) “The Psychological Reality of Practical Representation,” Philosophical Psychology 32: 784-821.

__ (forthcoming 2020) "Knowledge, Action, and Defeasibility," in J. Brown and M. Simion (eds.) Reasons, Justification, and Defeaters, Oxford: Oxford University Press.

- (forthcoming) "An Empirical Case for Practical Concepts," Synthese.

Poston, T. (2009) “Know How to Be Gettiered?” Philosophy and Phenomenological Research 79: 743-7.

Pritchard, D. (2012) “Anti-Luck Virtue Epistemology,” The Journal of Philosophy 109: 247-79.

Putnam, H. (1975) “The Meaning of 'Meaning,," in K. Gunderson (ed.) Language, Mind, and Knowledge, 131-93, Minneapolis, MN: University of Minnesota Press.

Ryle, G. (1949) The Concept of Mind, London: Hutchinson \& Co.

- (1967) "Teaching and Training," reprinted in G. Ryle, Collected Essays 1929-1968: Collected Papers Volume 2, 80-9, Abingdon: Routledge.

_ (1970) “Bertrand Russell 1872-1970," Proceedings of the Aristotelian Society 71: 77-84.

_ (1972) “Thinking and Self-Teaching," reprinted in G. Ryle, On Thinking, 18-23, Totowa, NJ: Rowman and Littlefield.

Schiffer, S. (2002) “Amazing Knowledge," The Journal of Philosophy 99: 200-2.

Schutz, A. (1976) Collected Papers Vol. II, Dordrecht: Springer.

Setiya, K. (2012) "Know How," Proceedings of the Aristotelian Society 112: 285-307.

Shmuelof, L., Krakauer, J. W., and Mazzoni, P. (2012) "How Is a Motor Skill Learned? Change and Invariance at the Levels of Task Success and Trajectory Control," Journal of Neurophysiology 108: 578-94.

Shusterman, R. (2008) Body Consciousness: A Philosophy of Mindfulness and Somaesthetics, Cambridge: Cambridge University Press.

Sosa, E. (2007) A Virtue Epistemology, Oxford: Oxford University Press. (2015) Judgment and Agency, Oxford: Oxford University Press.

Stanley, J. (2011a) Know How, Oxford: Oxford University Press.

- (2011b) "Knowing (How)," Noûs, 45: 207-38.

Stanley, J., and Williamson, T. (2001) “Knowing How,” Journal of Philosophy 98: 411-44.

(2017) "Skill," Noûs 51: 713-26.

Stanley, J., and Krakauer, J. W. (2013) "Motor Skill Depends on Knowledge of Facts," Frontiers in Human Neuroscience 7: 1-11.

Stichter, M. (2018) The Skillfulness of Virtue: Improving Our Moral and Epistemic Lives, Cambridge: Cambridge University Press. 


\section{Introduction}

Thomason, R. H. (1974) “Introduction” to Formal Philosophy: Selected Papers of Richard Montague, 1-69, New Haven, CT and London: Yale University Press.

Turri, J. (2018) "Virtue Epistemology and Abilism on Knowledge," in H. Battaly (ed.) The Routledge Handbook of Virtue Epistemology, 309-16, New York: Routledge.

Weatherson, B. (2017) "Intellectual Skill and the Rylean Regress," The Philosophical Quarterly 67: 370-86. Wiggins, D. (2012) "Practical Knowledge: Knowing How to and Knowing That," Mind 121: 97-130.

Zagzebski, L. (1996) Virtues of the Mind, Cambridge: Cambridge University Press. 
